
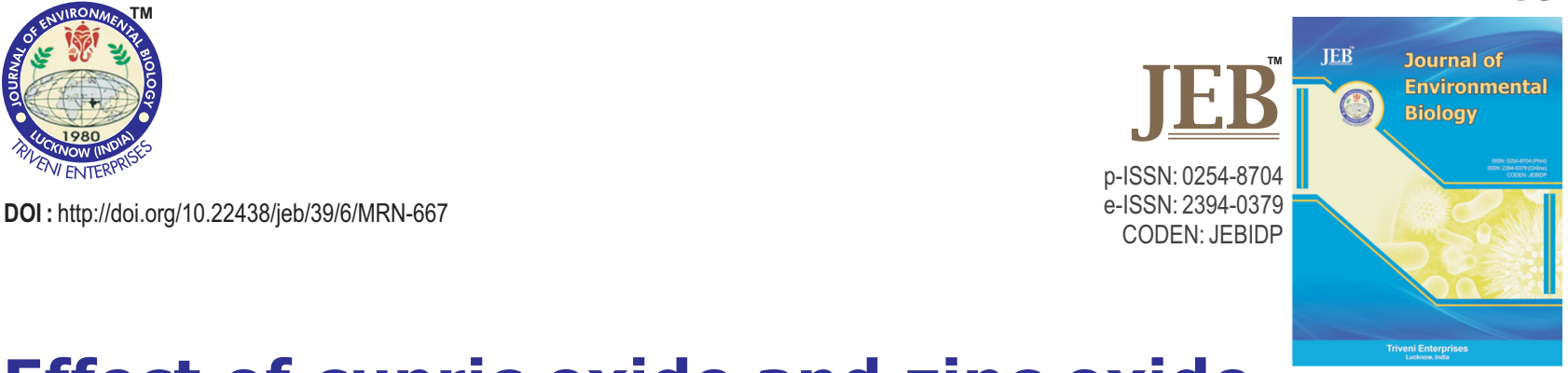

\title{
Effect of cupric oxide and zinc oxide nanoparticles on seed mycoflora and seed quality of fodder crops
}

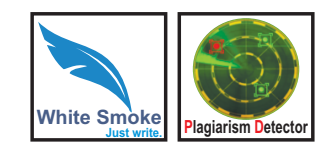

\section{Authors Info}

N. Manjunatha*', M. Prajapati ${ }^{2}$, V. Dunna', A. Maity', V.K. Wasnik', C.K. Gupta ${ }^{1}$ and S.S. Parmar

'Division of Seed Technology, ICAR-Indian Grassland \& Fodder Research Institute, Jhansi-284 003, India

2Department of Microbiology, Bundelkhand University,

Jhansi-284 128, India

*Corresponding Author Email : manjuigfri17@gmail.com

Key words

Antifungal

Fodder crops

Mycoflora

Nanoparticles

Spore germination

Publication Info

Paper received : 12.06 .2017

Revised received : 31.10 .2017

Re-revised received : 20.12.2017

Accepted : 04.01.2018

\section{Abstract}

Aim : Advancement in nanotechnology has amplified the effectiveness of traditional fungicides against pathogens when seeds are treated with nano formulation of fungicides. The present study was undertaken to investigate the effect of nanoparticles on seed mycoflora and seed quality parameters of fodder crops, in a view to accomplish nanoparticles application in near future.

Methodology : Fodder seed samples were subjected to standard blotter paper method and plated on Potato Dextrose Agar to isolate seed mycoflora. The major seed mycoflora were used as test organisms for further studies. Suspension of different concentrations $\left(5 \mathrm{mgl}^{-1}, 10 \mathrm{mg} \mathrm{l}^{-1}, 15 \mathrm{mg} \mathrm{l}^{-1}\right.$ and $\left.20 \mathrm{mg} \mathrm{l}^{-1}\right)$ of cupric oxide (CuO) and zinc oxide ( $\mathrm{ZnO}$ ) nanoparticles (NPs) were prepared from $200 \mathrm{mg} \mathrm{I}^{-1}$ stock suspension. The same concentrations of NPs were used for antifungal assay and to test effect on seed quality parameters.

Results : The results showed CuO NPs had greater antifungal impact on seed mycoflora than ZnO NPs. An incremental radial growth was observed with ZnO NPs at lower concentrations but at $20 \mathrm{mg} \mathrm{l}^{-1}$ growth was retarded as compared to control. The efficacy was directly correlated with the concentration and maximum reduction of spore germination was observed at $20 \mathrm{mg} \mathrm{l}^{-1}$. Nanoparticles enhanced seed germination, root length, shoot length and seedling dry weight at lower doses, but reduction was noticed at higher doses in all fodder crops studied.

Interpretation : These results suggest that $\mathrm{CuO}$ and $\mathrm{ZnO} N P$ s can be used as an effective seed protectant fungicide against seed mycoflora with proper standardization of concentration to overcome their phytotoxic effect.

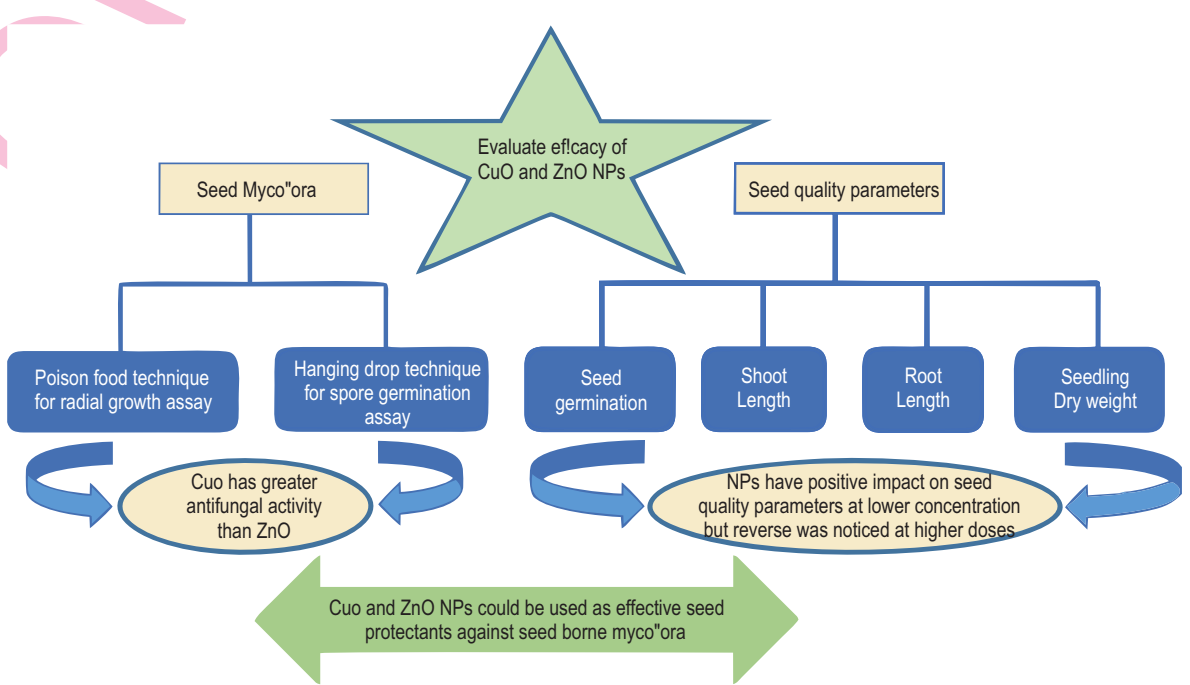




\section{Introduction}

Forage crops are vital components for dairy industries and few of them are also gaining importance as substrate for biofuel production (Gulbis et al., 2016). To sustain the dairy industry and rural economy, India requires an additional increase of more than 800 metric tons of fodder by 2030 (Datta, 2013). To attain this target, increase in continuous supply of good quality seeds is imperative, both as feed and input for crop production as well. Seeds with high initial vigour, foliage growth and good germination provide more biomass and also provides edge to weed competition in their natural growth conditions (Maity et al., 2016). One of the main impediments towards the availability of good quality seeds is seed borne pathogens (Naqvi et al., 2013; Kononenko et al., 2015), which account for annual economic loss of more than US \$130 million in Afro-Asian countries (Yago et al. 2011). They reduce seed viability by associating with the seed either externally or internally and may cause seed abortion, seed rot, seed necrosis and reduction or elimination of germination capacity as well as seedling damage. Besides, they grow on the seed substratum and produce mycotoxins which are hazardous to humans and animals as well (Cheli et al., 2013; Driehuis, 2013). Therefore, management of these pathogens during the seed-borne phase is considered to be crucial. For the last few decades, use of agrochemicals for seed treatment has certainly decreased the incidence of seed mycoflora, but at the same time has contributed to the development of resistant pathogens (Elad et al., 1992). Moreover, such chemicals can be lethal to beneficial microorganisms in the rhizosphere and useful soil insects, and they may also enter the food chain and accumulate in undesirable levels (Kononenko et al., 2015). With the emergence and proliferation of microbes resistant to fungicides and the burgeoning health care costs, many researchers have been tried to develop new and effective antimicrobial reagents that do not stimulate resistance and are less expensive. Nano scale materials have emerged as novel antimicrobial agents owing to their high surface area to volume ratio and the unique chemical and physical properties, which increases their contact with microbes and their ability to permeate cells (Wang et al., 2016).

Advancement in nanotechnology has amplified the effectiveness of traditional fungicides against pathogens when seeds are treated with nano formulation of fungicides (He et al., 2011; Ouda, 2014). However, different studies showed both positive and negative effects of nanoparticles on plants and microbes (Burke et al., 2015; Simonin et al., 2016; Singh et al., 2016). These nanoparticles not only act as antimicrobial agents but can also enhance seed germination, vigor and yield in a wide array of crops (Mukherjee et al., 2016). The nanoparticles of key elements/metals viz., $\mathrm{SiO}_{2}$, Silver, have been studied extensively for seed treatment (Le et al., 2014; Siddiqui and Al-whaibi, 2014). But, less emphasis has been given on metal based synthetic Nps nanoparticles to explore its antifungal property. The old as well as novel agrochemicals used nowadays for seed treatment have differential mode of action against seed pathogen (Kim et al.,
2012). Some of them impact the synthesis of DNA or RNA or protein of pathogen, whereas some influence the spore germination and growth of fungi (Yang et al., 2011). Although nanotechnology is a recently incepted tool in agriculture, its antifungal property has well been proved. But the mode of action of the NPs on pathogens has not been studied properly. Furthermore, scanty of literature is available on effect of nanoparticles on spore germination, fungal growth and its management in fodder crops through seed treatment with nanoparticles. Hence, the present experiment was undertaken to study the effect of copper and zinc based nanoparticles (NPs) on seed quality, fungal growth and spore germination.

\section{Materials and Methods}

Seed material and nano particles : Two-year-old fodder seed samples (Berseem, Cowpea, Sorghum and Oats) were collected from Seed Processing Unit, Division of Seed Technology, ICARIGFRI, Jhansi. The synthetic nano particles (Cupric oxide (CuO), APS: 40 nm; mol. wt.: 79.54; Zinc oxide (ZnO), APS: 240 nm; mol. wt.: 81.38) for this experiment were purchased from SRL Company Pvt. Ltd., Chennai, India

Isolation of seed mycoflora and nanoparticles treatment : Seed samples of fodder crops were subjected to standard blotter paper method and plated on potato dextrose agar (PDA) to isolate important mycoflora associated with Berseem, Cowpea, Sorghum and Oats. The major seed mycoflora were selected to be used as test organisms and were maintained on PDA medium. Suspension of different concentrations $\left(5 \mathrm{mg} \mathrm{l}^{-1}, 10 \mathrm{mg} \mathrm{l}^{-1} 15 \mathrm{mg} \mathrm{l}^{-1}\right.$ and $\left.20 \mathrm{mg} \mathrm{l}^{-1}\right)$ of NPs (CuO and $\mathrm{ZnO}$ ) were prepared from $200 \mathrm{mg} \mathrm{l}^{-1}$ stock suspension. The same concentrations were used for antifungal assay and to test their effect on seed quality parameters.

Antifungal assay : radial growth : In-vitro assay was performed on growth medium treated with $5 \mathrm{mgl}^{-1}, 10 \mathrm{mgl}^{-1}, 15 \mathrm{mgl}^{-1}, 20 \mathrm{mgl}^{-1}$ concentrations of NPs ( $\mathrm{CuO}$ and $\mathrm{ZnO}$ ). One $\mathrm{ml}$ of suspension was added with the help of micropipette into separate petri plate containing 15-20 ml of PDA medium before solidification and they were thoroughly mixed. After solidification uniform size of agar discs (diameter, $8 \mathrm{~mm}$ ) of selected fungi were inoculated at the centre of each petri plate containing different concentration of NPs, followed by incubation at $25 \pm 1^{\circ} \mathrm{C}$ for 7 days. After incubation, radial growth $(\mathrm{cm})$ was measured and recorded when growth of mycelia in the control plate reached the edge of the petri plate.

Spore germination : Spore germination study was carried out by "Hanging Drop Technique". The suspension of exudates and fungal spores (100-200) from one week old cultures were prepared to study the germination of fungal spores. All the tested fungi were individually picked up with a sterile inoculation needle and mixed in the different concentration ( $5 \mathrm{mg} \mathrm{l}^{-1}, 10 \mathrm{mgl}^{-1}, 15 \mathrm{mg} \mathrm{l}^{-1}$ and $20 \mathrm{mgl}^{-1}$ ) of NPs. For each experiment the suspension of fungal spores is placed on a cover slip, and then inverted over the concave depression of the slide to produce a hanging drop. The slides were 
then placed in moist chambers prepared by placing two moist filter papers in the inner surfaces of a Petri plate. Three replications were made for each suspension of fungal spores. Spores mixed in distilled water without leaf exudates served as the control. The slides were incubated at $25+2^{\circ} \mathrm{C}$ for 24 hrs and then fixed with cotton blue in lacto-phenol. Germination was observed after $24 \mathrm{hrs}$ under a light microscope and the images were captured with the help of a camera mounted stereo microscope. All the experiments were conducted in triplicate for each test fungus. The per cent spore germination was calculated.

Effect of NPs on seed quality parameters : The desired quantity of berseem, cowpea, oats and sorghum seeds were surface sterilized with $70 \%$ ethanol and then rinsed with sterile distilled water several times. The seeds were transferred to conical flask containing different concentration of NPs [control, 5 $\left.\mathrm{mg} \mathrm{l}^{-1}, 10 \mathrm{mg} \mathrm{l}^{-1}, 15 \mathrm{mg} \mathrm{l}^{-1}, 20 \mathrm{mg} \mathrm{l}^{-1}\right]$ and shaken at $120 \mathrm{rpm}$ for 4 hrs. The soaked seeds were taken out and shade dried. The standard germination test was followed (ISTA, 2008). Total 400 seeds in 4 hrs replicates of 100 seeds were put in germinator as per top of paper method. Seedling, shoot and root lengths and dry-weight were measured at the end of germination test.

Data analysis : Statistical analysis of each treatment was conducted with three replicates. The results were analyzed by one way ANOVA using statistical software SAS 9.3 version.

\section{Results and Discussion}

Mycoflora analysis of two-year-old seeds of fodder crops recorded different species. Among these most dominant mycoflora isolated were Aspergillus spp., Alternaria spp., Bipolaris spp., Colletotrichum spp., Curvularia spp., Fusarium spp., Penicillium spp. and Rhizopus spp. For experimental purpose, five species viz., Aspergillus niger, Alterneria alternata, Bipolaris spp., Curvularia lunata and Fusarium spp.were used to test antimycoflora activity of $\mathrm{CuO}$ and $\mathrm{ZnO} N P$ s.

According to the results of this study, $\mathrm{CuO}$ and $\mathrm{ZnO}$ NPs showed antifungal properties against seed mycroflora and concentration of NPs across the seed mycroflora had varied effect on both radial growth and spore germination (Table 1, 2). The antifungal effects of nanoparticles have been illustrated by many researchers (Cioffi et al., 2004; Min et al., 2009; Johari et al., 2014). The treatments at lower concentrations of CuO NPs showed non-significant impact on radial growth across seed mycoflora compared to control. However, relative decrease in radial growth and spore germination of all seed mycroflora was observed at higher concentration $\left(20 \mathrm{mg} \mathrm{l}^{-1}\right)$ in all tested seed mycoflora. The same trend was also observed by Kim et al. (2012). In agreement with our results, Johari et al. (2014) illustrated that the best antifungal effects of nanoparticles occurred at the highest concentrations.

Table 1 : Effect of $\mathrm{CuO}$ and $\mathrm{ZnO}$ nanoparticles on radial growth $(\mathrm{cm})$ of seed mycoflora of fodder crops

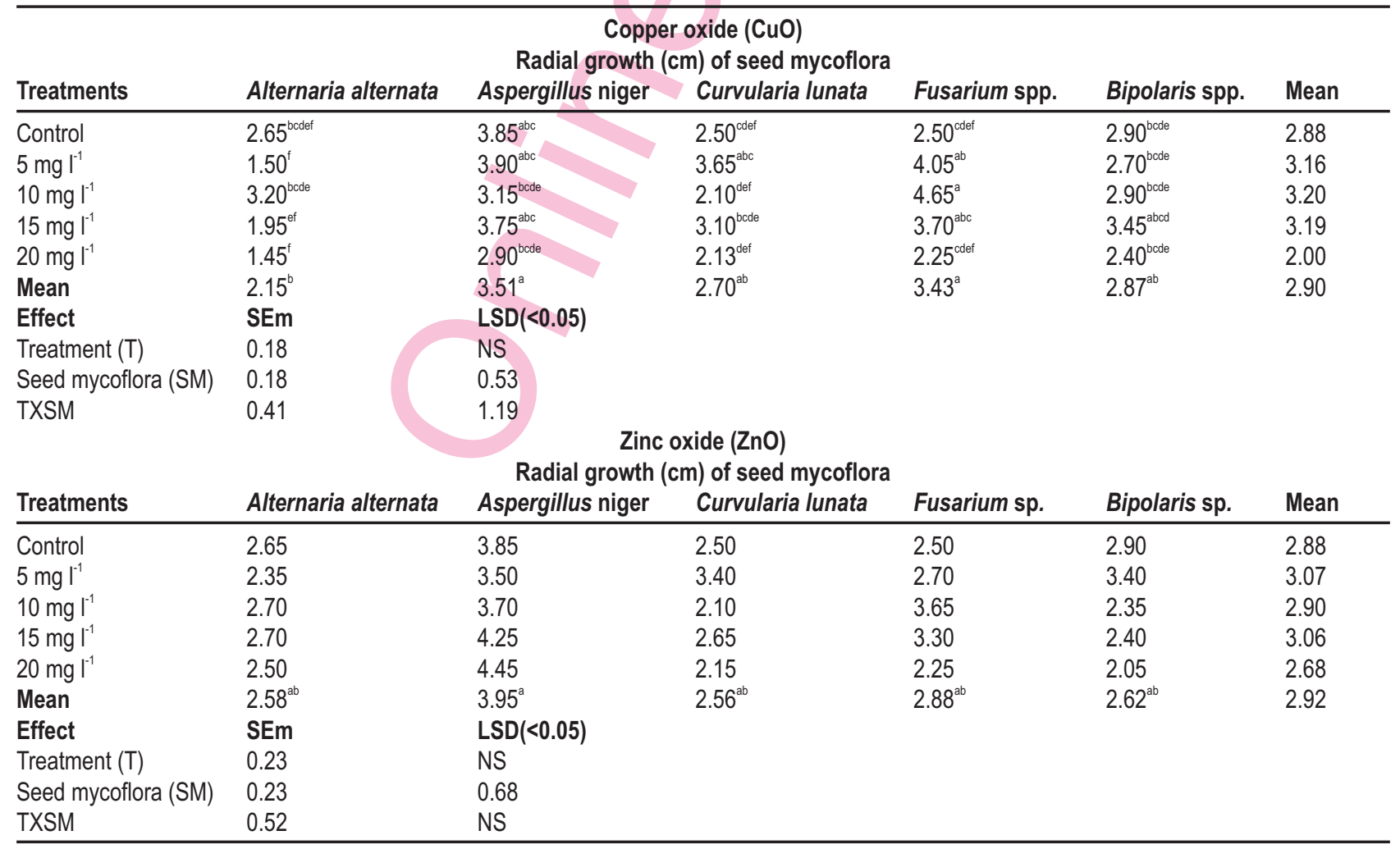

$\mathrm{a}, \mathrm{b}, \mathrm{c}$, etc. signifies the significant difference at $P<0.05$ 
Table 2 : Effect of $\mathrm{CuO}$ and $\mathrm{ZnO}$ nanoparticles on spore germination (\%) of seed mycoflora of fodder crops

\begin{tabular}{|c|c|c|c|c|c|c|}
\hline \multicolumn{7}{|c|}{$\begin{array}{l}\text { Copper oxide (CuO) } \\
\text { Spore germination }(\%) \text { of seed mycoflo }\end{array}$} \\
\hline Treatments & Alternaria alternata & Aspergillus niger & Curvularia lunata & Fusarium spp. & Bipolaris spp. & Mean \\
\hline Control & $86(68.08)^{\mathrm{ab}}$ & $85(67.50)^{\mathrm{ab}}$ & $85(67.22)^{a b}$ & $94(76.02)^{a}$ & $84.5(66.88)^{\mathrm{ab}}$ & $86.7(69.14)^{a}$ \\
\hline $5 \mathrm{mg} \mathrm{l}^{-1}$ & $72(58.11)^{\mathrm{bc}}$ & $47(43.28)^{\text {defgh }}$ & $36(36.87)^{\text {ghi }}$ & $88(70.95)^{\mathrm{a}}$ & $56(48.45)^{\text {cde }}$ & $59.8(51.53)^{b}$ \\
\hline $10 \mathrm{mg} \mathrm{l}^{-1}$ & $58(49.70)^{c d}$ & $37.5(37.76)^{\mathrm{fghi}}$ & $23.5(28.94)^{i}$ & $90(71.65)^{\mathrm{a}}$ & $52.5(46.43)^{\text {defgh }}$ & $52.3(46.90)^{b}$ \\
\hline $15 \mathrm{mgl}^{-1}$ & $54.5(47.60)^{\mathrm{def}}$ & $31(33.81)^{\mathrm{hi}}$ & $23.5(28.94)^{i}$ & $86(68.08)^{\mathrm{ab}}$ & $37(37.42)^{\text {tghi }}$ & $46.4(43.17)^{b}$ \\
\hline $20 \mathrm{mg} \mathrm{l}^{-1}$ & $72(58.11)^{\mathrm{bc}}$ & $38.5(38.35)^{\text {efghi }}$ & $40(39.23)^{\text {efghi }}$ & $86(68.50)^{\mathrm{ab}}$ & $41(39.68)^{\text {déghi }}$ & $55.5(48.77)^{b}$ \\
\hline Mean & $68.5(56.32)^{\mathrm{a}}$ & $47.8(44.14)^{c}$ & $41.6(40.24)^{\mathrm{c}}$ & $88.6(71.04)^{c}$ & $54.2(47.77)^{\text {bc }}$ & $60.14(51.90)$ \\
\hline Effect & SEm & $\operatorname{LSD}(<0.05)$ & & & & \\
\hline Treatment $(\mathrm{T})$ & 1.41 & 4.12 & & & & \\
\hline Seed mycoflora (SM) & 1.41 & 4.12 & & & & \\
\hline TXSM & 3.16 & 9.21 & & & & \\
\hline \multicolumn{7}{|c|}{ Zinc oxide $(\mathrm{ZnO})$} \\
\hline Treatments & Alternaria alternata & Aspergillus niger & Curvularia lunata & Fusarium sp. & Bipolaris sp. & Mean \\
\hline Control & $86(68.08)$ & $85(67.50)$ & $85(67.22)$ & $94(76.02)$ & $84.5(66.88)$ & $86.9(69.14)^{a}$ \\
\hline $5 \mathrm{mgl}^{-1}$ & $56(48.77)$ & $48(43.62)$ & $65(53.78)$ & $93(75.01)$ & $47(43.27)$ & $61.8(52.89)^{b}$ \\
\hline $10 \mathrm{mg} \mathrm{l}^{-1}$ & $54(47.34)$ & $59.5(50.50)$ & $41(39.81)$ & $90.5(72.84)$ & $43.5(41.26)$ & $57.7(50.35)^{b}$ \\
\hline $15 \mathrm{mg} \mathrm{l}^{-1}$ & $64(53.13)$ & $47(43.28)$ & $50(45.00)$ & $87(68.88)$ & $41(39.81)$ & $57.8(50.02)^{b}$ \\
\hline $20 \mathrm{mg} \mathrm{l}^{-1}$ & $50(45.00)$ & $37.5(37.75)$ & $28.5(32.22)$ & $76(61.43)$ & $40(39.20)$ & $46.4(43.12)^{b}$ \\
\hline Mean & $62(52.46)^{b}$ & $55.4(48.53)^{b}$ & $53.9(47.61)^{b}$ & $88.1(70.84)^{a}$ & $51.2(46.09)^{b}$ & $62.12(53.10)$ \\
\hline Effect & SEm & $\operatorname{LSD}(<0.05)$ & & & & \\
\hline Treatment $(\mathrm{T})$ & 2.48 & 7.21 & & & & \\
\hline Seed mycoflora (SM) & 2.48 & 7.21 & & & & \\
\hline TXSM & 5.53 & NS & & & & \\
\hline
\end{tabular}

$a, b, c$, etc. signifies significant difference at $P<0.05$

Possible mechanisms of action of metallic copper, copper ions and colloidal copper nanoparticles are based on changes in the structure and function of fungi cell; furthermore, these particles can affect DNA and disrupt its replication and transcription, which ultimately leads to the death of fungal microorganisms (Cioffi et al., 2004; Kalatehjari et al., 2015). But, in this study contradictory results were obtained with ZnO NPs. The radial growth of Aspergillus sp. increased with increase in the concentration of ZnO NPs in a consistent manner, whereas radial growth of remaining seed mycoflora was not positively correlated with increment in NPs concentration. He et al. (2011) clearly illustrated that inhibitory effect of ZnO NPs was dependent on incubation, concentration and microbial species.

The significant interactive effect between treatments and spore germination across the seed mycoflora was also observed in this study. Each genus of seed mycoflora responded significantly to the concentration of CuO NPs. Alternaria alternata showed maximum spore germination at control and minimum at $15 \mathrm{mg} \mathrm{l}^{-1}$. The results further indicated that the concentration $>5$ $\mathrm{mg} \mathrm{I}^{-1}$ can significantly decrease the spore germination of different seed mycoflora, except Fusarium sp. The treatment of ZnO NPs showed relatively lesser effect than $\mathrm{CuONPs}(\mathrm{P}<0.05)$. As a total, ZnO NPs treatment had significant a effect on the seed mycroflora, but failed to show significant effect on spore germination across the seed mycoflora at $5 \mathrm{mg} \mathrm{l}^{-1}$ to $15 \mathrm{mg} \mathrm{l}^{-1}$ concentration. At $20 \mathrm{mg} \mathrm{l}^{-1}, \mathrm{ZnO} \mathrm{NPs}$ was found effective in reducing spore germination of seed mycoflora than control. The microscopic observation of $\mathrm{CuO}$ and $\mathrm{ZnO}$ NPs treated spores revealed that most of the control spores were bright in appearance and produced long germ tubes after overnight incubation. This result is in agreement with Wagner et al. (2016) who studied the efficacy of $\mathrm{Zn}$ and $\mathrm{ZnO}$ NPs in reducing spore germination and inhibiting germ tube formation of Peronospora parasitica at higher concentration. It was also observed that an antimyflora activity of NPs may be due to suppression of enzymes and toxins used by the fungal pathogens for pathogenesis (Bhainsa and D'Souza, 2006; Vahabi et al., 2011).

The present study, both NPs across all concentrations enhanced seed germination significantly but at higher doses, in some cases, they reduced the germination. A similar trend was observed in several previous studies with crops and forage crops (Le et al., 2014; Maity and Natarajan, 2013; Maity et al., 2016). Enhanced enzymatic activities (Lu et al., 2002) improved nutrient sequestration on the seed surfaces by NPs (Navarro et al., 2008) and selective permeability of seed coats which prevents the inhibitory material to pass through it (Riahi-Madvar et al., 2012) have been suggested for these improvement in previous studies. 

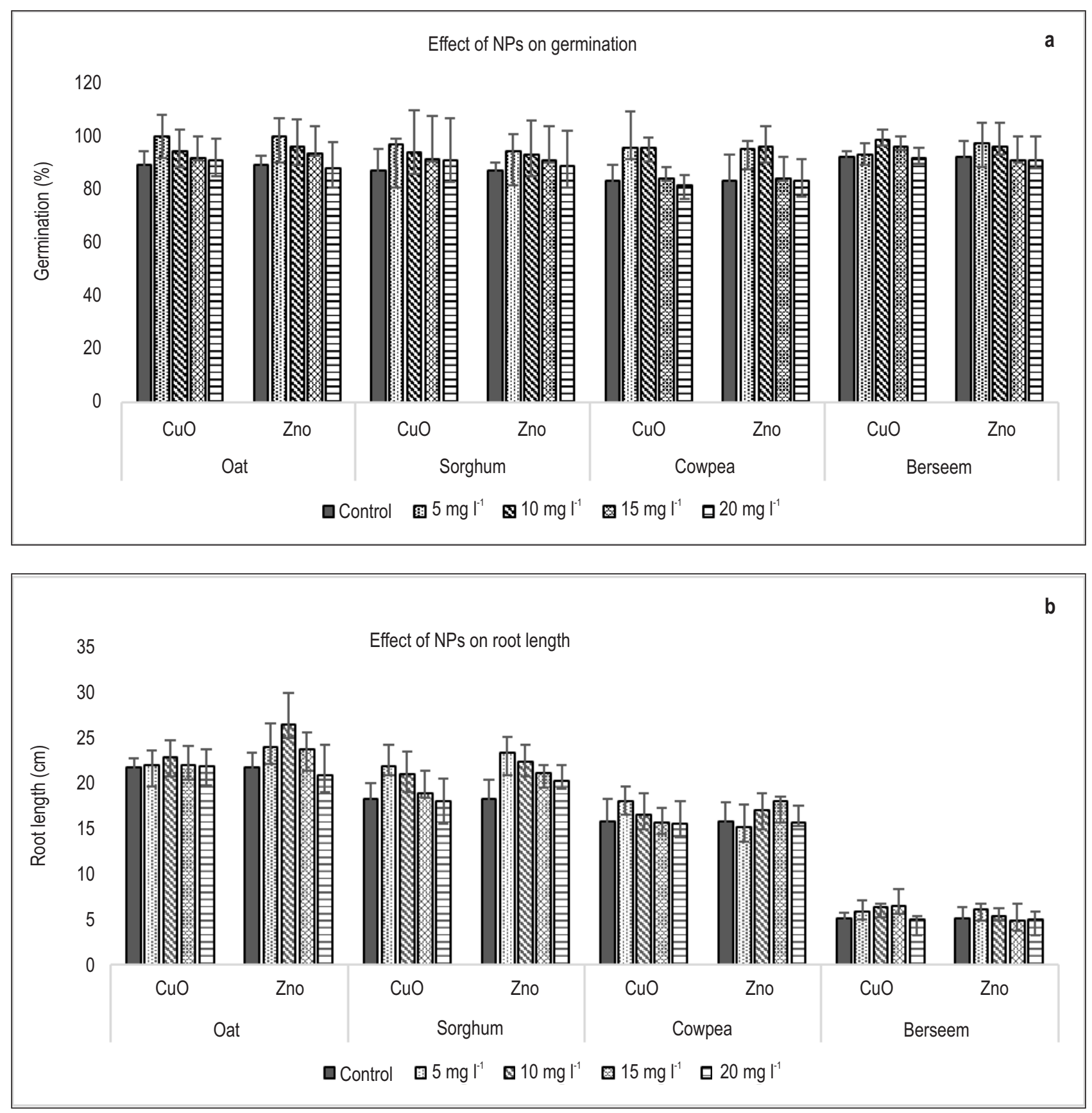

Fig .1 (a \& b) : Effect of $\mathrm{CuO}$ and $\mathrm{ZnO}$ nanoparticles on seed quality parameters of fodder crops.

In the present study a positive effect on root development across species and NPs concentration was observed (Fig. 1 b, c). Furthermore, in other studies no obvious effect of $\mathrm{nAl}_{2} \mathrm{O}_{3}$ on root elongation in cucumber, but positive effect on radish, rape and Arabidopsis thaliana has been reported (Lin and Xing, 2007; Le et al., 2014). In addition, as roots are the first organ to interact directly with the nanoparticles a dosage dependant response has been reported previously (Maity et al., 2016). The mechanism behind effect of nanoparticles on root elongation has not been clearly understood (Riahi-Madvar et al., 2012). However, it is believed that the anti-microbial properties of NPs provide roots with a competitive advantage over rhizosphere pathogen, thereby reducing competition for nutrients absorption.

In contrast, shoot length and dry weight studies showed a mix trend across different crops with different concentrations of 

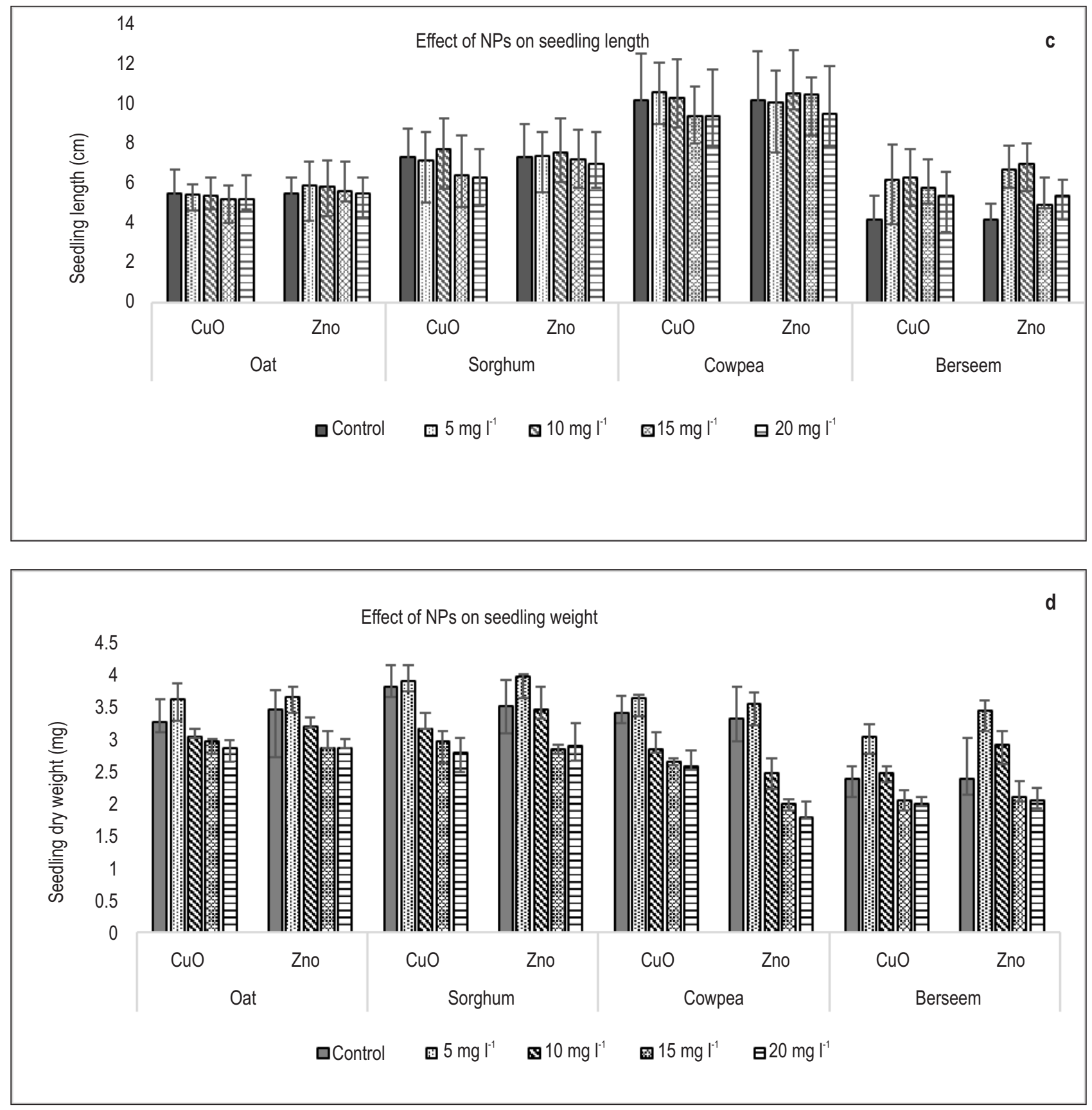

Fig .1 (c \& d) : Effect of $\mathrm{CuO}$ and $\mathrm{ZnO}$ nanoparticles on seed quality parameters of fodder crops.

NPs (Fig. $1 \mathrm{c}, \mathrm{d}$ ). A contrast between root development and shoot length and dry weight accumulation was observed (Fig. 1 b, c, d). Reportedly, this variability in shoot length and dry matter over root length could be attributed to the transportability of these nanomaterials to shoot and other organs through roots. A similar trend was observed in previous studies (Riahi-Madvar et al., 2012; Maity et al., 2016). Therefore, it may be concluded that higher the uptake of these particles by roots, more is the adverse effects on the growth parameter of seedlings. In summary little is known regarding the effects of $\mathrm{CuO}$ and $\mathrm{ZnO}$ based NPs on seed associated microorganisms because most of the studies have focused on silver NP against phytopathogenic mycoflora. This study clearly demonstrates that $\mathrm{CuO}$ and $\mathrm{ZnO} \mathrm{NPs}$ had significant antifungal activity over control. The NPs used in the present study had maximum effect at $20 \mathrm{mgl}^{-1}$ concentration. The antifungal activity of NPs differed with different seed mycoflora. 
Thus in view of environmental safety, cost effectiveness and fungicide resistance exhibited by continuous use of chemical fungicides the present study suggests that use of $\mathrm{CuO}$ and $\mathrm{ZnO}$ NPs is an alternative approach for the management of seed associated mycoflora via seed treatment. Before practical application of these NPs, further studies on several parameters are needed to evaluate including feasibility, phytotoxicity and antifungal effects in field as well as in storage conditions. Further, NPs tested in the investigation were supportive in enhancing the germination in all forage crops although a difference in response of the crops to NPs was recorded for all the traits under study. Apparently no toxicity for NPs was observed.

\section{Acknowledgment}

Facilities provided by the Director ICAR-IGFRI during the study is highly acknowledged.

\section{References}

Bhainsa, K. C. and S. F. D'Souza : Extracellular biosynthesis of silver nanoparticles using the fungus Aspergillus fumigatus. Colloids Surf. B: Biointerfaces, 47,160-164 (2006).

Burke, D. J., N. Pietrasiak, S.F. Situ, E. C. Abenojar, M. Porche, P. Kraj, Y Lakliang and A. C. Samia: Iron oxide and titanium dioxide nanoparticle effects on plant performance and root associated microbes. Int. J. Mol. Sci., 16, 23630-23650 (2015).

Cioffi, N., L. Torsi, N. Ditaranto, L. Sabbatini and P. Zamboni: Antifungal activity of polymer-based copper nanocomposite coatings. Appl. Phys. Lett., 85, 2417-2419 (2004).

Cheli, F., A. Campagnoli and V. Dell'Orto: Fungal populations and mycotoxins in silages: From occurrence to analysis. Anim. Feed Sci. Technol., 183, 1-16 (2013).

Datta, D.: Indian Fodder management towards 2030: A case of vision or myopia. Int. J. Manag. Soc. Sci. Res., 2, 33-419(2013).

Driehuis, F.: Silage and the safety and quality of dairy foods: A review. Agric. Food Sci., 22, 16-34 (2013).

Elad, Y., H. Yunis and T. Katan: Multiple fungicide resistance to benzimidazoles, dicarboximides and diethofencarb in field isolates of Botrytis cinerea in Israel. Plant Pathol., 41,41-46(1992).

Gulbis, K., B. Bankina, G. Bimšteina, I. Neusa-Luca1, A. Roga and D. Fridmanis: Fungal diversity of maize (Zea mays L.) grains. Rural Sustain. Res., 35, 1-6 (2016).

He, L., Y. Liu, A. Mustapha and M. Lin: Antifungal activity of zinc oxide nanoparticles against Botrytis cinerea and Penicillium expansum. Microbiol. Res., 166, 207-215(2011).

Johari, S. A., M. R. Kalbasi and I. J. Yu: Inhibitory effects of silver zeolite on in vitro growth of fish egg pathogen, Saprolegnia sp. J. Coastal Life Med., 2, 357-361 (2014).

Kalatehjaria, P., M. Yousefian and M. A. Khalilzadeh: Assessment of antifungal effects of copper nanoparticles on the growth of the fungus Saprolegnia sp. on white fish (Rutilus frisii kutum) eggs. Egypt. J. Aquat. Res., 41,303-306 (2015).

Kononenko, G.P., A. A. Burkin, O.P. Gavrilova and T.Y. Gagkaev: Fungal species and multiple mycotoxin contamination of cultivated grasses and legumes crops. Agric. Food Sci., 24, 323-330 (2015).

Kim, S. W., J. H. Jung, K. Lamsal, Y. S. Kim, J. S. Min and Y. S. Lee: Antifungal effects of silver nanoparticles (AgNPs) against various plant pathogenic fungi. Mycobiol., 40, 53-58 (2012).
Le, V. N., Y. Rui, X. Gui, X. Li, S. Liu and Y. Han: Uptake, transport, distribution and bio-effects of $\mathrm{SiO}_{2}$ nanoparticles in $\mathrm{Bt}$-transgenic cotton. J. Nano-biotechnol., 12, 50 (2014).

Lin, D. and B. Xing: Phytotoxicity of nanoparticles: Inhibition of seed germination and root growth. Environ. Pollut., 50, 243-250 (2007).

Lu, Y., Y. Yin, B.T. Mayers and Y. Xia: Modifying the surface properties of super paramagnetic iron oxide nanoparticles through sol-gel approach. Nano Letters, 2, 183-186 (2002).

Maity, A. and N. Natarajan, D. Vijay, R. Srinivasan, M. Pastor and D. R. Malaviya: Influence of metal nanoparticles (NPs) on seed germination and yield of forage oat (Avena sativa) and berseem (Trifolium alexandrinum). Proc. Natl. Acad. Sci. India: Biol. Sci. B., DOI 10.1007/s40011-016-0796-x (2016)

Min, J.S., K. S. Kim, S.W. Kim, J.H. Jung and K. Lamsal: Effects of colloidal silver nanoparticles on sclerotium forming phytopathogenic fungi. Plant Pathol. J., 25, 376-380 (2009).

Mukherjee, A., S. Majumdar, A. D. Servin, L. Pagano, O.P. Dhankher and J. C. White: Carbon nanomaterials in agriculture: A critical review. Front. Plant Sci., 7, 172(2016).

Naqvi, S. D. Y., T. Shiden, W. Merhawi and S. Mehret: Identification of seed borne fungi on farmer saved sorghum (Sorghum bicolor L.), pearl millet (Pennisetum glaucum L.) and groundnut (Arachis hypogaea L.) seeds. Agric. Sci. Res. J., 3, 107-114 (2013).

Navarro, E., A. Baun, R. Behra, N. B. Hartmann, J. Filser, A. Miao, A. Quigg, P. H. Santschi and L. Sigg: Environmental behavior and ecotoxicity of engineered nanoparticles to algae, plants, and fungi. Ecotoxicol., 17, 372-86 (2008).

Ouda, S. M.: Some nanoparticles effects on Proteus sp. and Klebsiella sp. isolated from water. Am. J. Infect. Dis., 2, 4-10 (2014).

Riahi-Madvar, A., F. Rezaee and V. Jalali: Effects of alumina nanoparticles on morphological properties and antioxidant system of Triticum aestivum. Ira. J. Plant Physiol., 3, 595-603 (2012).

Siddiqui, M.H. and M.H. Al-Whaibi: Role of nano-SiO in germination of tomato (Lycopersicum esculentum Mill.) seeds. Saudi J Biol Sci., 21, 13-17 (2014).

Simonin, M., A. Richaume, J. P. Guyonnet, A. Dubost, J.M.F. Martins and T. Pommier: Titanium dioxide nanoparticles strongly impact soil microbial function by affecting archaeal nitrifiers. Sci. Rep., $\mathbf{6}$, $33643(2016)$.

Singh, P., Y. J. Kim, D. Zhang and D. C. Yang: Biological synthesis of nanoparticles from plants and microorganisms. Trends Biotechnol., 34, 588-599 (2016).

Vahabi, K., G. A. Mansoori and S. Karimi: Biosynthesis of silver nanoparticles by fungus Trichoderma reesei. Inscience J., 1, 65-79 (2011).

Wagner, G., V. Korenkov, J. D. Jonathan and P. M. Bertsch: Nanoparticles composed of $\mathrm{Zn}$ and $\mathrm{ZnO}$ inhibit Peronospora tabacina spore germination in vitro and $P$. tabacina infectivity on tobacco leaves. Nanomaterials, 6, 50 (2016).

Wang, X., X. Yang, S. Chen, Q. Li, W. Wang, C. Hou, X. Gao, L. Wang and S. Wang: Zinc oxide nanoparticles affect biomass accumulation and photosynthesis in Arabidopsis. Front. Plant Sci., 6, 1243 (2016).

Yago, J.I., J. Roh, S. Bae, Y. Yoon, H. Kim and M. Nam: The effect of seed-borne mycoflora from sorghum and foxtail millet seeds on germination and disease transmission. Mycobiol., 39, 206218(2011).

Yang, C., C. Hamel, V. Vujanovic and Y. Gan: Fungicide: Modes of action and possible impact on non-target microorganisms, ISRN Ecology, Article ID 130289 (2011) 